\title{
Нитевидные нанокристаллы на основе фосфидных соединений, полученные методом молекулярно-пучковой эпитаксии на поверхности кремния
}

\author{
(ㄷ Г.Э. Цырлин ${ }^{1,2,3,4}$, Р.Р. Резник ${ }^{3}$, Ю.Б. Самсоненко ${ }^{1,2}$, А.И. Хребтов ${ }^{1,3}$, К.П. Котляр ${ }^{1}$, \\ И.В. Илькив ${ }^{1}$, И.П. Сошников ${ }^{1,2,4}$, Д.А. Кириленко ${ }^{4}$, Н.В. Крыжановская ${ }^{1}$ \\ ${ }^{1}$ Санкт-Петербургский академический университет Российской академии наук, \\ 194021 Санкт-Петербург, Россия \\ ${ }^{2}$ Институт аналитического приборостроения Российской академии наук, \\ 190103 Санкт-Петербург, Россия \\ ${ }^{3}$ Университет ИТМО, \\ 197101 Санкт-Петербург, Россия \\ ${ }^{4}$ Физико-технический институт им. А.Ф. Иоффе Российской академии наук, \\ 194021 Санкт-Петербург, Россия \\ E-mail: cirlin@beam.ioffe.ru
}

(Получена 25 апреля 2018 г. Принята к печати 7 мая 2018 г.)

\begin{abstract}
Приведены данные по росту и исследованию свойств наноструктур типа „вставка InAsP, внедренная в InP нитевидный нанокристалл“, выращенных на поверхности $\mathrm{Si}(111)$ методом молекулярно-пучковой эпитаксии с использованием золота в качестве катализатора. Установлено, что возможно получение практически $100 \%$ когерентных нитевидных нанокристаллов с поверхностной плотностью, варьируемой в широком интервале, и установлена взаимосвязь между структурными и оптическими свойствами выращенных нитевидных нанокристаллов. Показано, что исследуемые нитевидные нанокристаллы являются чистыми с точки зрения кристаллографической фазы (вюрцит). Предлагаемая технология открывает новые возможности по интеграции прямозонных соединений $\mathrm{A}^{\mathrm{III}} \mathrm{B}^{\mathrm{V}}$ и кремния.
\end{abstract}

DOI: 10.21883/FTP.2018.11.46588.10

\section{1. Введение}

Актуальность исследований нитевидных нанокристаллов (ННК) объясняется необходимостью решения важной задачи - создания новых непланарных полупроводниковых наноматериалов и наносистем с контролируемыми свойствами. Данные материалы могут быть использованы и уже используются при разработке приборов микроэлектроники, оптоэлектроники, аналитической биомедицины, эмиссионных катодов, зондов для сканирующей туннельной микроскопии, высокоэффективных преобразователей солнечной энергии и т.д. [13]. Гетероструктры на основе фосфидных соединений являются одними из наиболее исследуемых, так как их оптический диапазон охватывает как инфракрасную область излучения (например, твердые растворы на основе InAsP), так и видимый и ультрафиолетовый диапазоны (GaAsP, AlP и др.) Одним из важных преимуществ ННК является их возможность роста на „чужих подложках“ при сохранении высоких кристаллографических и оптических качеств. Это объясняется тем, что релаксация механических напряжений, неизбежно возникающих при росте соединений с разной постоянной решетки, эффективно снимается на боковых гранях ННК и формирование дефектов типа дислокаций несоответствия подавлено [4]. В связи с этим, рассматривая рост фосфидных ННК, оказывается возможным как рост на более дешевых подложках, чем фосфидные, так и формирование гетероструктур непосредственно в теле ННК. Кроме того, одним из свойств III-V ННК является их возможное формирование как в кубической, так и в гексагональной фазе. Данный эффект наблюдается для большинства III-V HHK (GaAs, InAs, $\mathrm{GaP}$, InP и т.д.) в различных ростовых технологиях, как при каталитическом росте на частицах $\mathrm{Au}$, так и в отсутствие катализатора, на подложках III-V и $\mathrm{Si}(111)$. Возможное чередование структур с различной кристаллической фазой приводит к формированию принципиально новых гетероструктур, например, так называемая „кристаллографическая квантовая точка“. Поэтому контроль кристаллической фазы в настоящее время рассматривается как одна из главных проблем на пути практического использования полупроводниковых ННК. Ранее нами исследовался рост гетероструктурных InP/InAsP HНК, выращенных на собственных подложках $[5,6]$. В настоящей работе нами сообщается о когерентном росте ННК в системе InP/InAsP/InP на поверхности $\mathrm{Si}(111)$ и исследовании их структурных и оптических свойств.

\section{2. Эксперимент}

Ростовые эксперименты проводились на установке молекулярно-пучковой эпитаксии Compact 21 фирмы Riber. Установка включает в себя отдельную камеру металлизации с эффузионным источником золота, из которой образец может быть перемещен в ростовую 
$a$
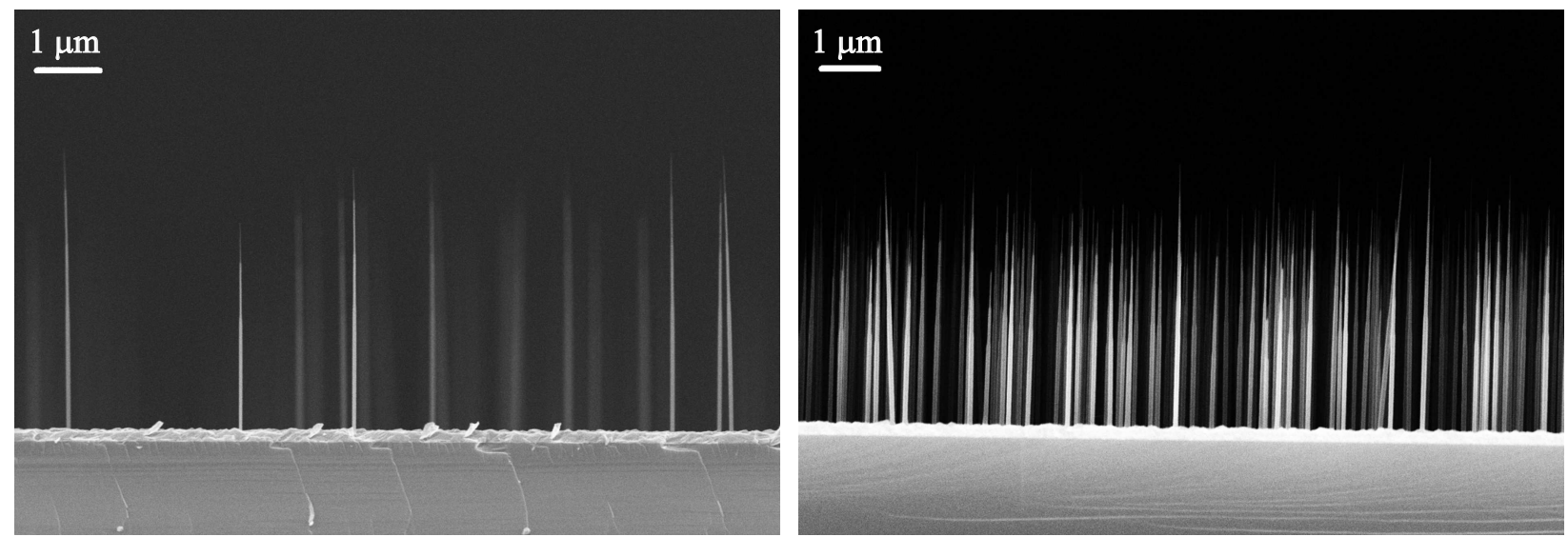

Pис. 1. СЭМ-изображения образцов ансамблей $\mathrm{InP} / \mathrm{InAsP} / \mathrm{InP}$ НHК с разным количеством напыленного золота: $a-0.1$ нм, $b-1$ нм перед ростом.

камеру без нарушения условий вакуума. В качестве подложек для МПЭ роста использовались пластины $\mathrm{Si}(111)$. На предварительном этапе кремниевые подложки проходили стандартную процедуру очистки в водном растворе плавиковой кислоты (1:10). Загруженная в камеру металлизации подложка нагревалась до $850^{\circ} \mathrm{C}$ для термической очистки, далее температура подложки понижалась до $550^{\circ} \mathrm{C}$ и напылялся слой золота толщиной $(0.1-1$ нм) для формирования нанометровых капель. Пластина со сформированными каплями катализатора перемещалась в ростовую камеру, оснащенную эффузионным источником индия и крекерными источниками мышьяка и фосфора, где подложка нагревалась до $250^{\circ} \mathrm{C}$. После стабилизации температуры подложки открывались заслонки индия и фосфора, и начинался синтез InP ННК. Поток In на поверхность подложки соответствовал скорости роста двумерного слоя $0.5 \mathrm{MC} / \mathrm{c}$. После $15 \mathrm{мин}$ роста на некоторое время (20 с) открывалась заслонка мышьяка для формирования InAsP-вставки. На завершающем этапе роста заслонка мышьяка закрывалась, рост InP продолжался еще в течение 5 мин для формирования покрывающего слоя тела ННК. Для исследования поверхности во время проведения ростовых экспериментов in situ использовался метод дифракции быстрых электронов на отражение (ДБЭО). Картины ДБЭО однозначно свидетельствовали о формировании ННК в вюрцитной фазе.

Исследование поверхностной морфологии проводилось методами растровой электронной микроскопии (РЭМ). Исследования фотолюминесценции (ФЛ) массивов НHК InP/InAsP/InP проводились при возбуждении YLF: $\mathrm{Nd}^{+3}$-лазером (длина волны $527 \mathrm{Hм,} \mathrm{мощ-}$ ность 10-500 мВт). Площадь лазерного пучка составляла $\sim 100$ мкм $^{2}$. Для детектирования сигнала использовались метод синхротронного детектирования, монохроматор Spectral Products DK-480 и однокональный InGaAs (Sciencetech) детектор.

\section{3. Результаты и их обсуждение}

На рис. 1 приведены типичные РЭМ-изображения массивов НHК InP/InAsP/InP, выращенных при разной толщине напыленного золота (0.1 и 1 нм соответственно). Очевидно, что поверхностная плотность существенно увеличилась для второго случая (более чем на порядок) таким образом, что число ННК пропорционально плотности сформированных золотых капель - катализаторов роста. Столь существенная степень свободы, позволяющая контролируемо варьировать поверхностную плотность ННК, важна для исследования локальных физических свойств ННК, когда необходимо изолированно измерять свойства именно одиночных ННК. С другой стороны, более плотный массив ННК позволяет исследовать коллективные свойства ансамблей ННК. Из рис. 1 следует, что средняя высота не зависит от поверхност-

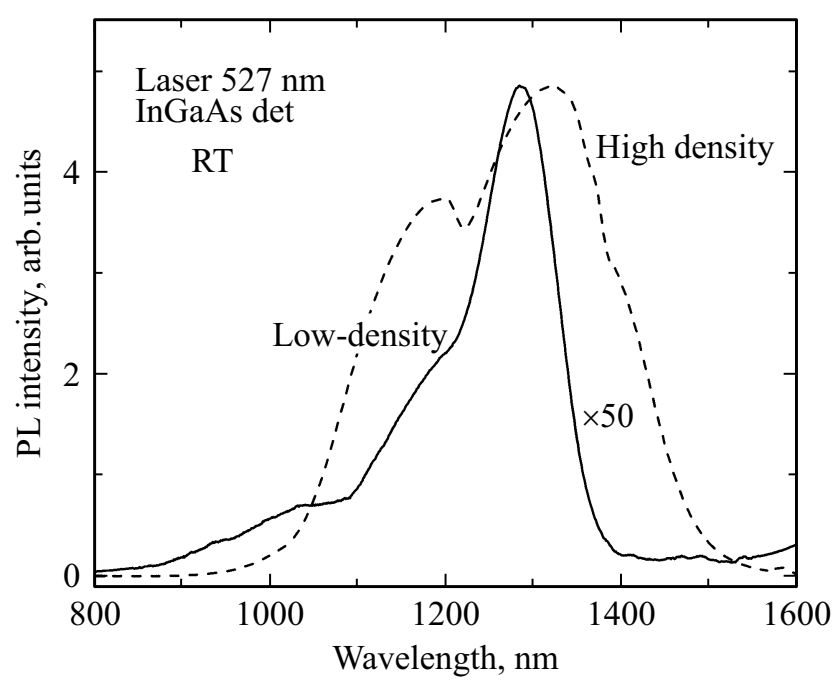

Pис. 2. Спектры ФЛ ансамблей InP/InAsP/InP НHК, показанных на рис. 1, снятые при комнатной температуре. 
$a$
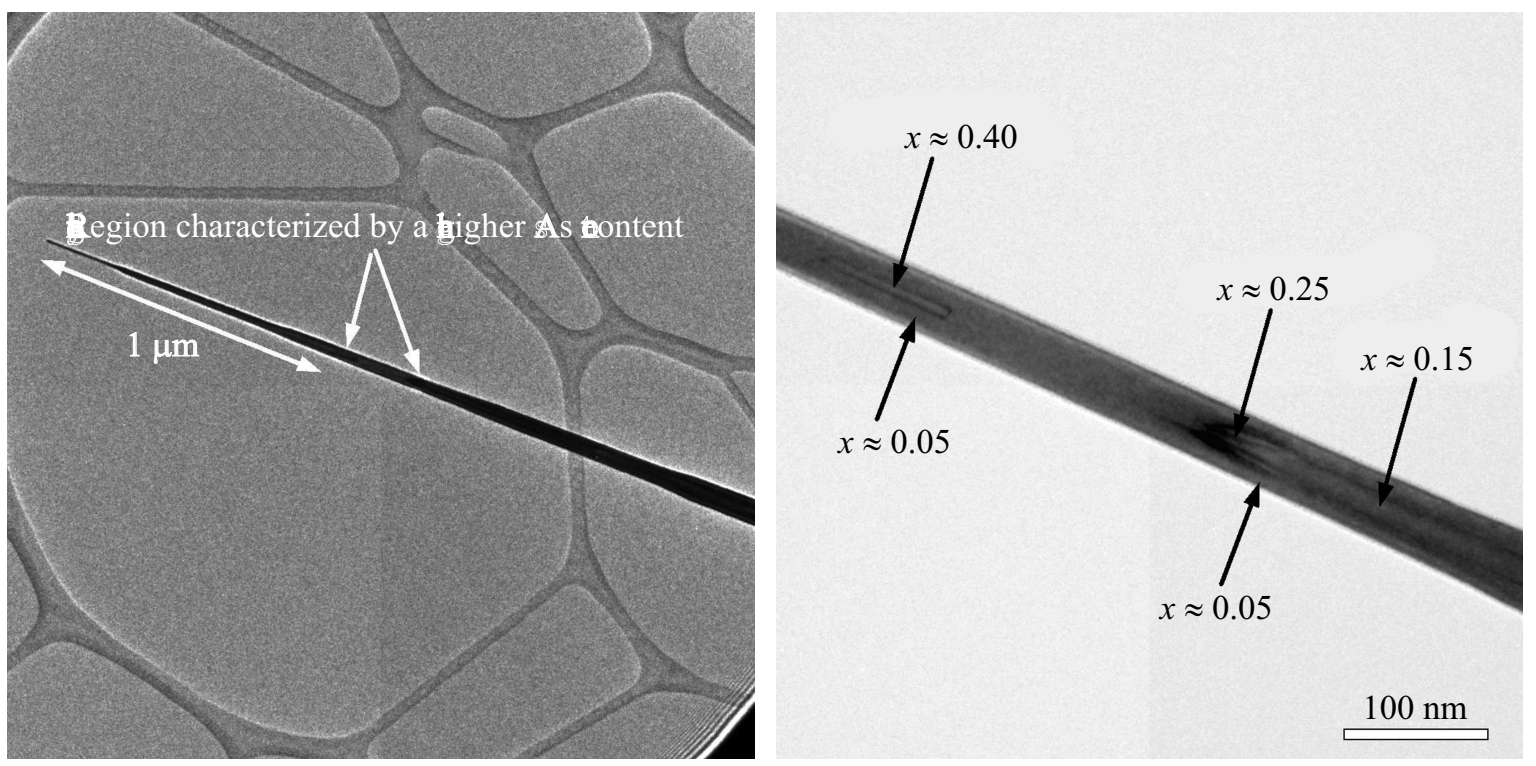

Рис. 3. ПЭМ-изображения одиночных InP/InAsP/InP ННК. $a$ - общий вид одиночного ННК, $b$ - верхняя часть ННК с указанием процентного содержания мышьяка.

ной плотности ННК и составила 4 мкм, а диаметр оказался неоднородным по высоте и составил 100 нм у основания и 30 нм на вершине ННК.

Следует отметить, что InP ННК сформировались преимущественно в направлении (111), лишь менее 5\% от всех ННК имели другие направления роста. Это связано со спецификой нанесения металлического слоя для формирования капель - катализаторов роста, а именно отсутствием этапа переноса подложки после напыления слоя в ростовую камеру установки МПЭ с нарушением вакуумных условий. В противном случае, в связи с быстрым формированием естественного окисного слоя на поверхности подложки, его дальнейшее удаление происходило бы при достаточно высокой температуре подложки $\left(\sim 950^{\circ} \mathrm{C}\right)$, что может приводить к нарушению когерентности роста.

На рис. 2 приведены спектры ФЛ от ансамблей $\mathrm{InP} / \mathrm{InAsP} / \mathrm{InP} / \mathrm{Si}(111)$ ННК, полученные при комнатной температуре наблюдения. Как и следовало ожидать, интегральная ФЛ интенсивность образца с меньшей поверхностной плотностью ННК значительно ниже, чем для образца с большой плотностью ННК. Тем не менее для оценки оптического качества структур было выполнено сравнение их интегральной интенсивности ФЛ с интенсивностью реперной структуры, оптический квантовый выход которой был близок к 100\%. Интегральная интенсивность ФЛ составляет 1 и 20\% для менее и более плотного образца соответственно, что свидетельствует об их высоком оптическом совершенстве. На спектрах ФЛ обоих образцов наблюдаются широкая полоса излучения в диапазоне $1000-1500$ нм, которая является суперпозицией нескольких линий ФЛ. Ширина линии ФЛ для менее плотного образца, однако, значительно меньше, чем для более плотного, что свидетельствует о большей однородности ННК, попадающих в область засветки лазера. Действительно, если в случае большей плотности общее количество возбуждаемых ННК более 1000, то в случае менее плотного - десятки. Для прояснения природы наблюдаемой ФЛ было проведено дополнительное исследование структуры ННК методом просвечивающей электронной микроскопии (ПЭМ).

На рис. 3 приведены типичное ПЭМ-изображение InP/InAsP/InP НHК, диспергированного на углеродную сетку, а также карта распределения мышьяка $(x)$ в различных частях ННК. Очевидно, что характер его распределения немонотонен. В ННК наблюдается образование преимущественно двух объектов: собственно вставки InAsP c характерными размерами 8 нм в диаметре и 100 нм по высоте со средним содержанием мышьяка $40 \%$ на расстоянии 1 мкм от вершины ННК, а также квантовой ямы (КЯ) InAsP со средним содержанием $15-25 \%$ по мышьяку вокруг тела ННК вследствие одновременного латерального роста материала во время формирования вставки. Таким образом, наиболее длинноволновые линии на спектрах ФЛ мы связываем с излучением из $\operatorname{InAs}_{1-x} \mathrm{P}_{x}$-вставок, вытянутых в направлении роста, соответствующим ширинам запрещенных зон объемного материала $\operatorname{InAs} s_{1-x} \mathrm{P}_{x}$. Более коротковолновые уширенные линии ФЛ соответствуют излучению от InAsP КЯ, представляющих собой радиальные слои толщиной несколько нанометров с различным составом по мышьяку.

Следует отметить, что исследуемые ННК оказались весьма чистыми с точки зрения кристаллографической 
фазы. Как уже отмечалось, для большинства материалов ННК являются плохо контролируемым изменением кристаллографической фазы внутри ННК даже на небольших расстояниях [7]. В нашем случае наблюдается формирование чистой вюрцитной фазы без формирования каких-либо структурных дефектов упаковки типа двойников или переброски кристаллографических фаз вюрцит - цинковая обманка, что является несомненным достоинством рассматриваемой системы InP/InAsP/InP/Si(111) ННК. По-видимому, это связано с используемой низкой температурой роста, что приводит к устойчивому росту слоев ННК под каплей катализатора на тройной границе „вакуум-капля-твердое тело“, что является необходимым условием для формирования ННК в вюрцитной фазе [8]. Кроме того, использование столь низкой температуры роста $\left(250^{\circ} \mathrm{C}\right)$ способствует возможной интеграции оптических элементов на кремниевой платформе с волоконно-оптическими системами связи.

\section{4. Заключение}

Таким образом, рассмотрен рост и исследованы свойства наноструктур типа „вставка InAsP, внедренная в InP НHК“, выращенных на поверхности $\mathrm{Si}(111)$ методом молекулярно-пучковой эпитаксии с использованием золота в качестве катализатора. Установлено, что возможно получение практически 100\% когерентных ННК с поверхностной плотностью, варьируемой в широком интервале, и установлена взаимосвязь между структурными и оптическими свойствами выращенных ННК. Показано, что исследуемые ННК являются чистыми с точки зрения кристаллографической фазы.

Данная работа выполнена при финансовой поддержке гранта РНФ № 14-12-00393. Синтез экспериментальных образцов выполнен при поддержке гранта РФФИ (грант № 18-32-00768 мол_а).

\section{Список литературы}

[1] В.Г. Дубровский, Г.Э. Цырлин, В.М. Устинов. ФТП, 43 (12), 1585 (2009).

[2] J. Ramanujam, A. Verma, B. González-Díaz, R. GuerreroLemus, C. Cañizo, E. García-Tabarés, I. Rey-Stolle, F. Granek, L. Korte, M. Tucci, J. Rath, U.P. Singh, T. Todorov, O. Gunawan, S. Rubio, J.L. Plaza, E. Diéguez, B. Hoffmann, S. Christiansen, G.E. Cirlin. Progr. Mater. Sci., 82, 294 (2016).

[3] A.V. Senichev, V.G. Talalaev, I.V. Shtrom, H. Blumtritt, G.E. Cirlin, J. Schilling, Ch. Lienau, P. Werner. ACS Photonics, 1 (11), 1099 (2014).

[4] F. Glas. Phys. Rev. B, 74, 121302 (2006).

[5] M. Tchernycheva, G.E. Cirlin, G. Patriarche, L. Travers, V. Zwiller, U. Perinetti, J.-Ch. Harmand. Nano Lett., 7, 1500 (2007).

[6] Г.Э. Цырлин, М. Tchernycheva, G. Patriarche, J.-C. Harmand. ФТП, 46 (2), 184 (2012).
[7] И.П. Сошников, Г.Э. Цырлин, А.А. Тонких, Ю.Б. Самсоненко, В.Г. Дубровский, В.М. Устинов, О.М. Горбенко, D. Litvinov, D. Gerthsen. ФTT, 47, 2121 (2005).

[8] F. Glas, J.C. Harmand, J. Patriarche. Phys. Rev. Lett., 99, 146101 (2007).

Редактор А.Н. Смирнов

\section{Phosphorus-based nanowires grown by molecular beam epitaxy on silicon}

G.E. Cirlin 1,2,3,4, R.R. Reznik ${ }^{\mathbf{3}}$, Yu.B. Samsonenko ${ }^{\mathbf{1 , 2}}$,

A.I. Khebrov ${ }^{\mathbf{1 , 3}, ~ K . P . ~ K o t l y a r ~}{ }^{\mathbf{1}}$, I.V. IIkiv',

I.P. Soshnikov ${ }^{1,2,4}$, D.A. Kirilenko ${ }^{4}$,

N.V. Kryzhanovskaya ${ }^{1}$

${ }^{1}$ St. Petersburg Academic University,

Russian Academy of Sciences,

194021 St. Petersburg, Russia

2 Institute for Analytical Instrumentation,

Russian Academy of Sciences,

190103 St. Petersburg, Russia

${ }^{3}$ ITMO University,

197101 St. Petersburg, Russia

${ }^{4}$ loffe Institute,

194021 St. Petersburg, Russia

Abstract The data on the growth peculiarities and physical properties of InAsP insertions embedded in InP nanowires (NWs) grown on $\mathrm{Si}(111)$ substrates by Au-assisted molecular beam epitaxy are presented. It is found that nearly $100 \%$ coherent to the substrate NWs may be grown within the wide range of the surface densities. The interplay between optical and structural properties of the grown structures is established. It is shown that grown NWs exhibit pure wurzite phase. The technology proposed opens new possibilities for the integration of direct-band $\mathrm{A}^{\mathrm{III}} \mathrm{B}^{\mathrm{V}}$ materials on silicon platform. 